\title{
Residents' perception of a mature and mass tourism destination: The determinant factors in Gran Canaria
}

Tourism Economics

I-20

(C) The Author(s) 2020

Article reuse guidelines: sagepub.com/journals-permissions DOI: 10.1 I77/13548|6620968330 journals.sagepub.com/home/teu

(S)AGE

\section{Pedro Ernesto Moreira Gregori 10 \\ University of Las Palmas de Gran Canaria, Spain}

\section{Concepción Román}

University of Las Palmas de Gran Canaria, Spain

\section{Juan Carlos Martín}

University of Las Palmas de Gran Canaria, Spain

\begin{abstract}
Residents' perception towards tourism has been studied in previous literature, but, in many cases, the analysis is based on studies of the impacts of new developments. In this study, we analyse the main determinant factors of residents' perception in Gran Canaria, a well-known mature and mass tourism destination in Europe. In addition to tourism, the analysis is extended towards the tourists themselves after more than 50 years of residents and tourists interaction. The analysis is based on a stratified random sample of 504 residents and ordinal logit models that extract the main determinant factors that explain different residents' perceptions towards tourism: (I) creation of new jobs; (2) development of infrastructures; (3) generation of wealth and economic growth; (4) the economy of the municipality; and towards tourists: (5) purchasing power; (6) behaviour; and (7) respect for the environment. The main determinant factors, the varied nuances and other third variables involved are obtained and commented. The article contributes empirically shedding some light in the complex phenomenon of residents' perception towards tourism and tourists.
\end{abstract}

\section{Keywords}

determinant factors, Gran Canaria, mass tourism, mature destination, residents' perception

\section{Corresponding author:}

Pedro Ernesto Moreira Gregori, TIDES (Institute of Tourism and Sustainable Economic Development), University of Las Palmas de Gran Canaria, PC 35017 Las Palmas GC, Spain.

Email: pedromoreira@ulpgc.es 


\section{Introduction}

The intrinsic difficulty raised in the studies on the social perception of tourism has been pointed out by several authors. The approach by Monterrubio (2008) emphasizes the need for more comparative studies that should consider the different contexts and realities. At a theoretical level, the author highlights the lack of standard measurements and methodologies that impede obtaining conclusions and generalized results. These difficulties might be causing, in many occasions, that published studies obtain opposite conclusions on similar situations. Similarly, Sharpley (2014) also concludes that the lack of consensus regarding measures and methodologies and the enormous diversity of contexts and destinations hinder the basis for the analysis of real case studies. The establishment of a general model of study or planning methodology becomes utopic and quinmerac.

However, the social exchange theory (SET) is emerging as the most commonly accepted theory. Nunkoo et al. (2013) argue that SET is used by the $56.3 \%$ of the theoretical publications that analyse the residents' perception towards tourism. Ap (1992) is one of the first authors employing SET, emphasizing as unit of analysis the relation of exchange itself and the processes involved. The perceptions of the residents would be influenced by the perceived positive and negative impacts, existing a rational evaluation of the advantages and disadvantages of such an exchange (Andereck et al., 2005).

In the context of this exchange, different figures occur in the residents' imaginary regarding the tolerance threshold for the load-carrying capacity of the destination. Doxey (1975) proposes the index of tourist irritation or 'Irridex Model' to measure such threshold. The author relates different stages of tourist development that are characterized by phases of euphoria, apathy, annoyance and antagonism. In addition, Dogan (1989) analyses the strategies of residents on tourism development as resistance, retraction, maintenance of limits, revitalization and adoption. While Ap and Crompton (1993) raised four consecutive phases: adoption, tolerance, adjustment and withdrawal. Regarding the typology of residents apropos the position towards tourism, Davis et al. (1988) propose five different types: (1) those who hate tourism; (2) those who love it; (3) the romantic cautious ones; (4) the intermediates; and (5) those who love it for some motive or reason.

Albeit there are a number of studies on residents' perception of tourism, there is still scarce information regarding the mass and mature tourist destinations as well as the residents' perception on some traits of tourists themselves. For example, although it is true that the literature of residents' perception towards tourism is not scant, the topic has been mainly studied on the economic and environmental impacts, and much less is known on the perception towards the tourists themselves. Filling this knowledge gap is pertinent, especially in these turbulent moments in which some tourism-phobia movements are appearing in some mass tourist destinations. For this reason, our analysis establishes the main determinants of residents' perception towards the tourists' purchasing power, general behaviour and respect for the environment. This can be considered one of the novel features of the study.

From the managerial perspective, a better understanding of the determinant factors that affect the residents' perception in Gran Canaria is also very valuable. Different stakeholders and policy makers can also use the obtained results in order to develop a set of well-adjusted measures that enhance a more aligned residents' perception towards tourism.

Thus, the objective of this study is to shed some light on this complex phenomenon by obtaining the main determinant factors of residents' perception towards tourism and tourists themselves in the island of Gran Canaria (Spain): one well-known mass and mature international tourist destination in the world. The analysis is based on ordinal logit models estimations from the data 
provided by a survey aimed at residents in Gran Canaria. Concretely, there are seven different models (four for tourism and three for tourists) that obtain the main determinant factors of the residents' perception regarding: (1) creation of new jobs; (2) development of infrastructures; (3) generation of wealth and economic growth; (4) the economy of the municipality; (5) tourists' purchasing power; (6) tourists' behaviour; and (7) tourists' respect for the environment.

\section{Literature review}

We start with a detailed overview of the 'thematic reviews' that have been published, and that we consider to be the most classic and pioneering in the framework of studies that analyse the residents' perception on tourism and its effects on the destination. Monterrubio (2008) cites Doxey (1975) as one of the first theoretical contributions in the analysis of residents' perception towards tourism with the development of the tourist irritation index model or 'Irridex Model'. The model recognizes the unfavourable impacts that tourism development could cause in the destination community. The tourism development consists of four stages that would explain the responses of the host communities: euphoria, apathy, annoyance and antagonism. Such irritation would be determined according to the degree of incompatibility between the interests of residents and tourists.

Secondly, the model by Dogan (1989) proposes various attitudinal strategies of residents facing the effects of tourism: resistance, withdrawal, maintenance of limits, revitalization and adoption. The author suggests that if tourism does not become an integral part of the host community's socioeconomic life, the response is likely to be one of resistance. For the Ap and Crompton (1993) models, the reaction of residents to tourism could be considered as a continuum integrated by four strategies: adoption, tolerance, adjustment and withdrawal.

Other some general theories are relevant and are cited as explanatory of the phenomenon, mainly the SET and that of social representations. Within a tourism framework, SET postulates that individual's attitudes towards tourism would be influenced by their evaluation of impacts on the community (Andereck et al., 2005). Therefore, within the framework of the exchange between residents and visitors, the costs and benefits generated would be rationally evaluated. On the other hand, the theory of social representations focuses on how to understand qualitatively the representation made by the host community residents of the interactions between the community and the tourists that guide the actions and decisions to be made (Fredline and Faulkner, 2000; Pearce et al., 1996).

Three additional 'thematic reviews' serve to highlight some theoretical attempts that have not been common in the topic, the type of research conducted and the necessity of extending conceptually the SET approach. First, Harrill (2004) reviews the studies on residents' attitudes towards tourism and classifies them according to socio-economic factors, spatial factors, economic dependency, measurement of resident typologies, residents' attitudes about tourism development and theoretical aspects such as community attachment, the aforementioned SET and the growth machine theory. The author highlights the categories provided by Davis et al. (1988) who classify residents in a wide range that runs from those who 'hate tourism' to those who 'love it'. Harrill (2004) develops the theoretical perspectives on community attachment by citing Mccool and Martin (1994) who define it as the type of integration, participation and intensity of the feeling of integration in community life. On the other hand, the growth machine theory focuses on the interests and alliances that emerge in support of urban growth: particularly useful for understanding the differences of opinion of residents and local elites regarding urban development.

Second, Nunkoo et al. (2013) provide an analysis based on the content analysis methodology of 140 articles published from 1984 to 2010 . The authors point out that most of the research is quantitative in 
nature, with mixed methods approaches, and that review articles are not frequent. Interestingly, they conclude that most of the studies have an atheoretical nature. Of the theoretical articles, the great majority applied, in order of importance: SET and the positivist paradigm, the life cycle of tourist destination and the Irridex Model. They also point out that several new theories have recently emerged in research, and that the combination of quantitative and qualitative methods is likely to optimize the rigour of studies, and, consequently, it offers new perspectives and advances in the area.

And more recently, Sharpley (2014) aligns with one of the criticisms that is usually made of SET as a conceptual framework, as, in reality, the perceptions are configured within a broader sociocultural and historical framework. Thus, the focus on a particular form of social exchange tends to ignore the broader and more diverse sociocultural context within the exchange occurs. The author considers that it is important not to exclude tourists from the equation, who also have opinions, perceptions and expectations that would in turn condition the opinions and attitudes of the residents.

Nowadays, tourism is becoming a global occurrence in the world as tourists are travelling to more destinations more frequently. The phenomenon is partly due to technological advances and the rise of low-cost airlines. Thus, travel flows around the world have greatly increased, and tourism boom has put the focus on the negative externalities of overcrowding and 'overtourism'. According to Dodds and Butler (2019), overtourism is 'a new term for an old problem', associated to an excessive number of tourists which causes all kinds of negative effects in the destination community. Overtourism has especially affected certain urban centres in some iconic destinations such as Venice, Barcelona, Rome, Dubrovnik, Berlin or Prague that have assisted to significant residents' protest demonstrations. Capocchi et al. (2019) affirm that overtourism is a complex phenomenon on which there is no general consensus regarding the thematic approach, origin, characteristics, scope or the appropriate measures to counteract its negative effects.

We end this section with two recent empirical studies on the topic. Li et al. (2019) analysed 63 destinations in China and concluded that the residents showed mostly positive attitudes towards tourism development. The main reasons cited for the positive perception are that it facilitates local economic development, promotes the protection of culture as well as the construction of infrastructure. The evaluation of economic improvement was enough to outweigh the environmental deterioration. The authors also observed that as tourism development is more consolidated, some negative effects, like, for example, environmental deterioration, social conflicts and a higher cost of living, began to be more clearly perceived.

And finally, Robinson et al. (2019) remarked that environmental protection and active planning participation are important areas that need to be taken into account when the topic is analysed. The authors conclude that residents' perceptions of environmental deterioration reduce support for tourism development; $50 \%$ of the respondents perceived that tourism was the main cause of marine degradation and could also exacerbate community conflicts that lead to less social cohesion. Support for tourism development was greater among those surveyed who actively participated in the planning process.

\section{Methodology for the analysis of ordered responses}

Ordinal models are regression models that are used in cases where the dependent variable acquires an orderly manner and with different categories. The ordinal logit model used in the study has the form of latent regression

$$
Y *=\beta^{\prime} X+\varepsilon
$$


$Y *$ is the dependent and latent variable that is not directly observed. $\beta^{\prime} X$ is the measurable part that is represented as a linear combination of unknown parameters and explanatory attributes or explanatory variables (determinant factors) and $\varepsilon$ is the random error that follows a logistic distribution in this case. The dependent variable is measured by a set of indicators in the following way

$$
\begin{aligned}
& Y=0 \text { if }-\infty<Y * \leq \mu_{0} \text { with } \mu_{0}=0 \\
& Y=1 \text { if } \mu_{0}<Y * \leq \mu_{1} \\
& Y=2 \text { if } \mu_{1}<Y * \leq \mu_{2} \\
& Y=3 \text { if } \mu_{2}<Y * \leq \mu_{3} \\
& Y=4 \text { if } \mu_{3}<Y * \leq \mu_{4}=+\infty
\end{aligned}
$$

$\mu_{j}$ forms a set of unknown parameters to be estimated that indicates the limits of each category. It should be noted that for this model the recoding begins at 0 in order to identify all the parameters of the threshold values. Through these hypotheses, the ordinal logit model allows us to estimate the unknown parameters $\beta$ and the threshold values that define the categories $\mu_{j}$ as well as the probability of belonging to the different categories for each respondent. In relation to the interpretation of the parameters, it is noted here that if $\beta$ is estimated with positive sign, it means that the probability of being in the higher category is higher, meanwhile the probability of being in the lower category is lower. The opposite logic occurs if $\beta$ is estimated with a negative sign.

Ordinal models were introduced by Mckelvey and Zavoina (1975), developing similar assumptions to linear models that are better suited when the observed dependent variable is ordinal. These models represent an extension of the probit dichotomous model and assume in turn that the ordinal nature of the dependent variable is due to methodological limitations of the data collection. The model assumes a linear effect of each independent variable as well as a series of break points or rupture between the categories of the dependent variable. A more up-to-date theoretical-practical guide to ordinal logit models can be consulted in Greene and Hensher (2010). In this guide, the authors propose models of ordered choice through a methodology that allows to explain the influences in the choice made between a set of ordered alternatives. The methods have evolved into a considerable level of sophistication that allows a great heterogeneity in the parameters of the thresholds, in the explanatory variables and in the decomposition of the residual variance.

In our case, in order to analyse the main determinant factors that explain different residents' perceptions towards tourism, seven different ordinal logit models have been estimated: four models that analyse the perception on economic impacts (creation of new jobs, development of infrastructures, generation of wealth and economic growth and the economy of the municipality) and three models that analyse the perception on individual tourists' traits (the purchasing power, behaviour and respect for the environment). In each of the models, a different set of explanatory variables has been considered according to the previous literature and the significance of the econometric estimations. The models have been estimated using the software NLogit 6 (Greene, 2015), and all the parameters are obtained by maximum likelihood.

\section{Data}

The data used in this article come from a survey of 504 residents of the island of Gran Canaria, administered between 6 and 29 June 2012, with quotas according to gender and tourist or nontourist residence area and with a confidence level of $95 \%$ (Table 1). The island of Gran Canaria 
Table I. Main socio-demographic variables of respondents.

\begin{tabular}{lr} 
Residence area & \\
Tourist area & 45.4 \\
Non-tourist area & 54.6 \\
Work or has been employed at tourism & \\
Yes & 32.0 \\
No & 68.0 \\
Work or has been employed at tourism (relative) & \\
DK/NA & 0.2 \\
Yes & 44.0 \\
No & 55.9 \\
Gender & \\
Man & 49.5 \\
Woman & 50.5 \\
Age group & \\
I8-29 years old & 19.0 \\
$30-44$ years old & 25.8 \\
$45-59$ years old & 32.9 \\
60 years old or more & 22.2 \\
Studies level & \\
Without studies & 0.7 \\
Elementary School (EGB) & 33.9 \\
High School or Vocational Training (BUP, ESO, FPI) & 19.4 \\
Bachelor or Advanced Vocational Training & 27.8 \\
University & 17.5 \\
DK/NA & 0.8 \\
Income & \\
DK/NA & 18.6 \\
Less than 500 & 7.8 \\
$50 I-I 000$ & 22.6 \\
I00I-I500 & 20.1 \\
I5OI-2000 & 11.0 \\
$200 I-2500$ & 8.8 \\
$250 I-3000$ & 5.5 \\
More than $3000 €$ & 5.5 \\
\hline
\end{tabular}

Source: Own elaboration.

Note: DK/NA: Don't know / Not Applicable.

has 21 municipalities of which 2 have been declared tourist municipalities (San Bartolomé de Tirajana and Mogán). In general, some tourists visit a large part of the island, especially its capital city, Las Palmas of Gran Canaria. It is noted here that the percentage of residents in the tourist municipalities is very low $9.1 \%$, and for this reason, and in order to be more representative of the phenomenon under study, it was decided to raise the quota of these two municipalities up to $45.4 \%$. The gender was used as a second stratification variable (female, $50.5 \%$; male, $49.5 \%$ ).

As said, the main objective of the study was to find the determinant factors of the residents' perception towards a number (seven) of impacts of tourism and tourists themselves. Thus, the questionnaire was developed in order to obtain a number of positive and negative impacts of the 
tourism development in the island. A second group of questions was more related to the residents' attitudes and preferences according to the types of tourists and the interaction with them. A third part also included questions about the general situation of tourism and some tourist policies. The fourth and final part also included the main socio-demographic variables of the residents.

Table 1 shows the residents' profile, most respondents do not work and have not worked in tourism (68\%). In any case, it can be seen that the importance of this economic sector in the island is very important, as $32 \%$ of the respondents do work or have worked in the sector. This figure increases up to $44 \%$ if we include those who have a relative working in the industry. The largest age group is $45-59$ years old $(32.9 \%)$, then the groups: from 30 years to 44 years old $(25.8 \%)$, 60 years old or more $(22.2 \%)$ and $18-29$ years old (19\%). Considering the highest level of studies achieved, the most representative group corresponds to Elementary School (33.9\%), followed by Bachelor or Advanced Vocational level (27.8\%). Significantly, lower percentages of studies have the respondents with High School (19.4\%) and university educational level (17.5\%). The most frequent income is obtained in the range of the income from $501 €$ to $1000 €(22.6 \%)$, followed by between $1001 €$ and $1500 €(20.1 \%)$. It can be seen that these two groups represent an important part of the sample of residents $(42.7 \%)$.

In this case, the valued latent variables measure the residents' perception towards a number of different issues that were considered object of the study. As said, there are seven issues under study that can be categorized into three different modules. The first module includes three latent variables: (1) the influence of tourism in the creation of new jobs; (2) the influence of tourism in the development of the infrastructures; (3) the influence of tourism in the generation of wealth and economic growth. In this first module, the answer format was established as a five-point semantic differential scale as follows: Very negatively $(Y=0)$; Negatively $(Y=1)$; Neither positive nor negative (does not affect) $(Y=2)$; Positively $(Y=3)$; and Very positively $(Y=4)$. The second module includes the issue of the importance of tourism in the economy of the Municipality of residence of the respondent. In this case, the response categories were based on a four-point semantic differential scale: Not important at all $(Y=0)$; Unimportant $(Y=1)$; Quite important $(Y=2)$; and Very important $(Y=3)$. Finally, the third module includes three different issues of the residents' perception towards some traits of tourist themselves with different answer formats. For example, the purchasing power of tourists was measured as $\operatorname{Low}(Y=0)$; Medium $(Y=1)$; and High $(Y=2)$. The behaviour of tourists was measured as Very unpleasant $(Y=0)$; Unpleasant $(Y=1)$; Normal $(Y=2)$; Nice $(Y=3)$; and Very nice $(Y=4)$. And finally, the respect for the environment by tourists was measured according to the scale: Not at all $(Y=0)$; Little $(Y=1)$; Enough $(Y=2)$; and Very respectful $(Y=3)$. The importance of using different scales of questions improves the reliability of the answers: as it decreases the bias caused by the automatic responses. In this way, the respondent is forced to be more reflexive and not to automatically answer a series of questions with the same value by inertia.

\section{Analysis and results}

This section presents the results of the analysis carried out in relation to the determinant factors about resident's perceptions towards tourism and tourists. In order to facilitate the interpretation of the results, Table 2 shows the definition of the variables used as well as the denomination in the different models.

As dependent variables we have selected variables related to the most visible and expected impacts of tourism in the destination: creation of new jobs, development of the infrastructures 
Table 2. Variables used in the models.

Dependent variables

Influence of the tourism in the creation of new jobs

Influence of the tourism in the development of the infrastructures (communications, urban equipment)

Influence of the tourism in the generation of wealth and economic growth

Importance of the tourism for the economy of the Municipality

Perception about the tourists: their purchasing power

Perception about the tourists: their behaviour

Perception about the tourists: their respect for the environment

Explanatory variables

\begin{tabular}{|c|c|}
\hline Variable name & Definition of the variable in the model \\
\hline MAN & $=\mathrm{I}$ if the respondent is a man \\
\hline INCOUPLE & $=\mathrm{I}$ if the respondent lives in couple \\
\hline AGE & Age of the respondent \\
\hline INCOME & $=\mathrm{I}$ if income is higher than $\mathrm{I} 500 €$ \\
\hline TOURMUNICIP & $\begin{aligned}= & \text { I if Municipality of residence is San Bartolomé de Tirajana or Mogán. Tourist } \\
& \text { municipality }\end{aligned}$ \\
\hline LPGC & $=\mathrm{I}$ if Municipality of residence is Las Palmas de Gran Canaria \\
\hline TOURJOB & $=\mathrm{I}$ if the resident works or has worked in the tourism industry \\
\hline TOURJOBRELATIVE & $=\mathrm{I}$ if the resident has a relative who works or has worked in the tourism industry \\
\hline HASTRAV & $=1$ if the resident has made some leisure trip during the last 12 months \\
\hline TOURISINTER & $=\mathrm{I}$ if the resident has a regular interaction with tourists \\
\hline TOURISTREATM & $=\mathrm{I}$ if the resident believes that the treatment given to the tourist is good or very good \\
\hline PPIO_I & $\begin{array}{l}=\mathrm{I} \text { if the resident agrees or agrees very much with: 'The jobs that tourism generates } \\
\text { are of bad quality' }\end{array}$ \\
\hline PPI0_2 & $\begin{array}{l}=I \text { if the resident agrees or agrees very much with: 'Tourism has had a positive effect } \\
\text { in the natural resources and the landscape' }\end{array}$ \\
\hline PPIO_3 & $\begin{aligned}= & I \text { if the resident agrees or agrees very much with: 'Most of the jobs that tourism } \\
& \text { creates are occupied by immigrants' }\end{aligned}$ \\
\hline PPIO_4 & $\begin{aligned}= & \mathrm{I} \text { if the resident agrees or agrees very much with: 'Facing the future, it would be } \\
& \text { necessary to resign from tourism and to think about other alternative developments' }\end{aligned}$ \\
\hline PPI0_5 & $\begin{aligned}= & \mathrm{I} \text { if the resident agrees or agrees very much with: 'Most of the wealth that tourism } \\
& \text { generates benefits companies that are out of the island' }\end{aligned}$ \\
\hline PPI0_6 & $\begin{array}{l}=I \text { if the resident agrees or agrees very much with: 'Thanks to tourism, the } \\
\text { unemployees have more opportunities to obtain a good job' }\end{array}$ \\
\hline PPIO_7 & $\begin{array}{l}=1 \text { if the resident agrees or agrees very much with: 'The quality of the tourists who } \\
\text { visit our island has improved in the last years' }\end{array}$ \\
\hline PPI0_8 & $\begin{aligned}= & \mathrm{I} \text { if the resident agrees or agrees very much with: 'The tourist offer (hotels, } \\
& \text { restaurants) of Gran Canaria is of very good quality' }\end{aligned}$ \\
\hline PPIO_9 & $\begin{array}{l}=\mathrm{I} \text { if the resident agrees or agrees very much with: 'It is necessary to increase the } \\
\text { number of persons that visits the island' }\end{array}$ \\
\hline PPI4_2 & $\begin{array}{l}=\mathrm{I} \text { if the resident agrees or agrees very much with: 'The tourists spend little money } \\
\text { generating few benefits' }\end{array}$ \\
\hline PPI4_4 & $\begin{array}{l}=I \text { if the resident agrees or agrees very much with: 'The tourist area of the south } \\
\text { of the island will not support any newer buildings' }\end{array}$ \\
\hline
\end{tabular}


Table 2. (continued)

Explanatory variables

PPI4_5

PPI4_6

PPI4_7

PPI4_8
$=\mathrm{I}$ if the resident agrees or agrees very much with: 'The possible oil-bearing prospects will endanger the beaches of Fuerteventura and Lanzarote as tourist resources'

$=\mathrm{I}$ if the resident agrees or agrees very much with: 'The tourist moratorium has stopped the investments and the tourist growth in the Canary Islands'

$=\mathrm{I}$ if the resident agrees or agrees very much with: 'With the shutdown of the construction, tourism has become the main exit of the crisis'

$=\mathrm{I}$ if the resident agrees or agrees very much with: 'The tourist area of the south of the island has too many obsolete facilities and it is necessary to renew them'

Source: Own elaboration.

(communications, urban equipment), generation of wealth and economic growth and importance of tourism to the economy of the Municipality. Other variables related to the residents' perception towards tourists themselves such as the purchasing power, the behaviour and the respect for the environment were also included as dependent variables.

And as explanatory variables of the residents' perception regarding the dependent variables, a selection variables is obtained: (1) socio-demographic variables (such as gender, marital status, age, Municipality of residence and work or have worked in tourism); (2) tourist behavioural variables (travel in the last 12 months, interaction and treatment with tourists); and (3) other variables of opinion on the effects of tourism on the destination (mentioning phrases and value judgements regarding tourism development and its positive and negative impacts on the island).

The tables corresponding to the results of the estimates presented in the following sections show the value of the estimated coefficient, its standard error, the value of the statistic corresponding to the $t$-test of significance and the extremes of the confidence interval for the true value of the parameter. In most cases, the estimated parameters were significant at $90 \%$ of confidence, that is, with a $t$-test in an absolute value greater than 1.65. Only in rare exceptions the significance of the estimates was lower than $90 \%$ (between $85 \%$ and $88 \%$ ), and due to the relevance of the variable in each of the models, it was finally decided to leave the variables within the models.

\section{Creation of new jobs, development of the infrastructures, generation of wealth and economic growth}

In general terms, the opinions are very positive when evaluating the influence of tourism in the creation of new jobs, in the development of the infrastructures, as well as in the generation of wealth and economic growth.

It is noteworthy in this module of questions that the highest valuation given by respondents is on the capacity of tourism for the creation of new jobs (Table 3). It can be seen that the responses are being positive and very positive for $7(72.6 \%)$ out of 10 respondents. This result is not a surprise as in addition to the significant weight of tourism in GDP (30\%), the unemployment rates have always been high, being, precisely, hospitality a direct source of employment for $30 \%$ of the working population. Although the influence of tourism on employment is considered negative for almost $2(18.2 \%)$ out of 10 respondents, this assessment may be related to the low remuneration and the poor qualification of such jobs. In addition, it is noteworthy that the quality of the tourism 
Table 3. Opinions about important tourism impacts in Gran Canaria.

\begin{tabular}{lccc}
\hline & $\begin{array}{c}\text { Creation } \\
\text { of new jobs }\end{array}$ & $\begin{array}{c}\text { Improvement of } \\
\text { the Infrastructures }\end{array}$ & $\begin{array}{c}\text { Generation of wealth } \\
\text { and economic growth }\end{array}$ \\
\hline DK/NA & 0.0 & 1.1 & 0.7 \\
Negatively & 18.2 & 19.8 & 14.4 \\
$\begin{array}{l}\text { Neither positive nor negative } \\
\text { (it does not affect) }\end{array}$ & 9.2 & 12.0 & 15.7 \\
$\begin{array}{l}\text { Positively } \\
\text { Very positively }\end{array}$ & 70.5 & 65.0 & 65.3 \\
\hline
\end{tabular}

Source: Own elaboration.

Note: DK/NA: Don't know / Not Applicable.

employment in the Canary Islands is better than in other Spanish areas with high tourist seasonality (Mediterranean coast), where a type of a more precarious employment contract is common, the so-called 'fijo-discontinuo'.

From the survey, $32 \%$ of the respondents work or have worked in tourism, and $44 \%$ have a relative who works or has worked in the sector. Of the first collective, almost 8 out of 10 respondents consider tourism as the most important sector in the island's economy. And while being aware of the importance of tourism, they are also more critical with tourist development. Especially in relation to the quality of the tourism employment, the development of the infrastructures, the increase in the cost of housing in tourist areas, the purchasing power of tourists and their respect for the environment (Moreira et al., 2017).

Rodríguez (2007), in a study conducted in Andalusia, highlights that the critical opinion on the effects of tourism in the creation of new jobs is also shared by those who work or have worked in tourism. In this case, the author identifies as disadvantages the low salaries, the high temporality and the over qualification. Similarly, the same results are obtained by Andereck et al. (2005) in the published study on the opinions of residents in Arizona (USA). For their part, Marrero and Huete (2013) emphasize, in a study on the Valencia Community, the ambiguity of the opinions of respondents in recognizing the economic relevance of tourism, and, in turn, the bad or precarious working conditions in the sector. Other published studies highlight the favourable views about tourism of the people who work in the sector: (1) the city of Cappadocia-Turkey by Tosun (2002); (2) the city of York-United Kingdom by Snaith and Haley (1999); and (3) the island of Samos of Greece by Haralambopoulos and Pizam (1996).

The next most valued aspect is the generation of wealth and economic growth, being positive and very positive for 7 (69.2\%) out of 10 respondents. As this question is so generic, we could interpret the concept of wealth generation as an index, which could include among others, indicators of improvement of the quality of life, the job creation and the improvement in the living conditions. Rodríguez (2007) also notes that Andalusian people mostly believe that tourism has also a positive effect on the job creation and on the generation of wealth and economic development.

The influence of tourism on the development of the infrastructures is also highly considered by Gran Canaria residents, $67.2 \%$ of residents value it positive and very positively. However, for almost twenty percent of respondents, the impact is negative because the evaluation is moderated by the overcrowding problems or the obsolescence of some of the constructions. 
Table 4. Estimations on the creation of new jobs.

\begin{tabular}{lccrrr}
\hline & & & & \multicolumn{2}{c}{ Confidence interval } \\
\cline { 5 - 6 } Variable & Coefficient & Standard error & $t$-Ratio & Lower bound & Higher bound \\
\hline Constant & 0.7404 & 0.2777 & 2.67 & 0.1961 & 1.2848 \\
INCOUPLE & 0.6172 & 0.3664 & 1.68 & -0.1008 & 1.3353 \\
TOURMUNICIP & 1.1193 & 0.2356 & 4.75 & 0.6576 & 1.5810 \\
TOURJOB & -0.4592 & 0.2251 & -2.04 & -0.9003 & -0.0181 \\
HASTRAV & 0.5397 & 0.2027 & 2.66 & 0.1423 & 0.9370 \\
PPI0_I & -0.4669 & 0.2304 & -2.03 & -0.9185 & -0.0153 \\
PPI0_6 & 0.6828 & 0.2121 & 3.22 & 0.2670 & 1.0986 \\
PPI4_4 & 0.4297 & 0.2194 & 1.96 & -0.0004 & 0.8598 \\
$\mu_{1}$ & 0.6729 & 0.0899 & 7.49 & 0.4968 & 0.8491 \\
$\mu_{2}$ & 5.1627 & 0.2457 & 21.02 & 4.6812 & 5.6442 \\
\hline
\end{tabular}

Source: Own elaboration.

The development of the infrastructures and equipment is also highlighted in some of the studies on the effects of tourism in Andalusia (Moreira, 2011; Rodríguez, 2007), where some negative perception is also obtained by those who reside in the tourist areas of the Costa del Sol (Malaga).

The results of estimates for the first model are presented in Table 4. It can be seen that the respondents who live in a couple, reside in a tourist municipality, have travelled in the last 12 months and agree or very much agree that: thanks to tourism the unemployed people have more opportunities to get a good job, and the south of the island would not support any newer buildings, are those who have a higher probability to have an opinion that tourism has a positive impact on the creation of new jobs.

On the contrary, those who work or have worked in tourism or those who agree or very much agree that tourist jobs are of bad quality are the ones who consider the opposite result and think negatively about the influence of tourism in the creation of new jobs (Rodríguez, 2007).

Regarding the impact of tourism on the development of the infrastructures (Table 5), the positive impacts are observed for the demographics based on being men and residing in a tourist municipality. Regarding the level of agreement with some tourist assessments, the positive impacts are observed for the residents who agree much or very much with the opinion that the unemployed people have more opportunities to get a good job. It is not easy to compare our results with others obtained by previous studies as in other studies, the results are based on more general perceptions about positive impacts of tourism. In this sense, there are studies of reference that indicate that men have more favourable perceptions towards tourism: (1) in the city of Charleston-South CarolinaUSA (Harrill and Potts, 2003); (2) a rural area in New Zealand (Mason and Cheyne, 2000); and (3) in the city of York-United Kingdom (Snaith and Haley, 1999).

Contrarily, those determinant factors which tend to induce more negative perceptions on the influence of tourism on the improvement of infrastructures are (1) those who work or have worked in tourism and (2) those who agree or very much agree with the judgements that, in the future, it would be necessary to resign from the tourism and to think about other development alternatives, and that most of the wealth that generates the tourism benefits companies that are of out of the island. 
Table 5. Estimates on the development of the infrastructures.

\begin{tabular}{lccrrr}
\hline & & & & \multicolumn{2}{c}{ Confidence interval } \\
\cline { 5 - 6 } Variable & Coefficient & Standard error & $t$-Ratio & Lower bound & Higher bound \\
\hline Constant & 1.5304 & 0.2580 & 5.93 & 1.0247 & 2.0361 \\
MAN & 0.4091 & 0.1907 & 2.15 & 0.0354 & 0.7828 \\
TOURMUNICIP & 0.6754 & 0.2147 & 3.15 & 0.2547 & 1.0962 \\
TOURJOB & -0.4068 & 0.2117 & -1.92 & -0.8216 & 0.0081 \\
PPI0_4 & -0.3741 & 0.2436 & -1.54 & -0.8515 & 0.1033 \\
PPI0_5 & -0.5797 & 0.1986 & -2.92 & -0.9689 & -0.1905 \\
PPI0_6 & 0.4399 & 0.1958 & 2.25 & 0.0561 & 0.8237 \\
$\mu_{1}$ & 0.7929 & 0.0882 & 8.99 & 0.6200 & 0.9659 \\
$\mu_{2}$ & 4.9874 & 0.2440 & 20.44 & 4.5092 & 5.4657 \\
\hline
\end{tabular}

Source: Own elaboration.

Table 6. Estimates of wealth generation and economic growth.

\begin{tabular}{lccrrr}
\hline & & & & \multicolumn{2}{c}{ Confidence interval } \\
\cline { 5 - 6 } Variable & Coefficient & Standard error & $t$-Ratio & Lower bound & Higher bound \\
\hline Constant & 1.4538 & 0.2312 & 6.29 & 1.0008 & 1.9069 \\
INCOUPLE & 0.7848 & 0.3600 & 2.18 & 0.0792 & 1.4904 \\
TOURMUNICIP & 0.8131 & 0.1977 & 4.11 & 0.4257 & 1.2006 \\
INCOME & 0.5223 & 0.2121 & 2.46 & 0.1066 & 0.9379 \\
PPI0_3 & -0.4489 & 0.1978 & -2.27 & -0.8365 & -0.0613 \\
PPI4_4 & 0.3427 & 0.2077 & 1.65 & -0.0644 & 0.7497 \\
$\mu_{1}$ & 0.9933 & 0.1025 & 9.69 & 0.7925 & 1.1942 \\
$\mu_{2}$ & 4.8797 & 0.2079 & 23.47 & 4.4722 & 5.2872 \\
\hline
\end{tabular}

Source: Own elaboration.

Regarding the generation of wealth and economic growth, Table 6 shows that those who live in a couple, reside in a tourist municipality, have an income less than $1500 €$ and agree or very much agree with the judgement that the tourist area of the south of the island will not support any newer buildings are the most likely to have a positive perception of the tourism influences. On the other hand, the residents who believe that the jobs that tourism creates are mainly occupied by immigrants are those who have less probability to consider that tourism is a source of wealth and economic growth.

\section{Importance of tourism for the economy of the municipality}

The importance of tourism for the economy of the municipality of residence is included in the questionnaire to evaluate the possible existing differences regarding the spatial distribution of the tourist activity. Almost 8 (75.9\%) out of 10 respondents consider that tourism is very important for 
Table 7. Opinions about the importance of the tourism in the economy of the Municipality.

Importance for the economy of the Municipality

Very important

41.8

Quite important

34.1

Little important

19.2

Not important at all

4.9

Source: Own elaboration.

the economy of the municipality of residence (Table 7). The data are relevant as only 2 of the 21 municipalities in Gran Canaria are considered eminently 'tourist' municipalities: San Bartolomé de Tirajana and Mogán, where only $9.1 \%$ of the inhabitants of the island reside. It is necessary to highlight here that the variable 'tourist zone' or 'non-tourist zone' was one of the variables of stratification of the survey, but it was finally decided to have a similar representation due to the nature of the study. In any case, it is evident that the results show that the importance of tourism transcends these two tourist municipalities and the influence of tourism is spread to the whole of the island as there is only one of every four $(24.1 \%)$ who does not give importance to tourism in the economy of the municipality.

It is clear that residing in a tourist municipality is a determinant factor that explains in part the residents' perception towards tourism and tourists. Vázquez et al. (2017), in a study of Benalmádena (Málaga-Spain), Moreira (2011), analysing Andalusia, and Moreira (2014), analysing Gran Canaria, conclude that residing in a tourist area is a conditional variable for the residents' perception. In the case of Benalmádena, an eminently tourist municipality, the residents distinguish more positive and negative impacts than the rest of the residents of the province. In this case, the majority of the residents consider that the impact of tourism in the locality is positive, but there are some residents who express concerns about negative externalities. On the other hand, both in the cases of Andalusia and Gran Canaria, it is observed that residents of the most touristic areas (Costa del Sol in Malaga and south of Gran Canaria) also perceive more positive and more negative impacts than residents of non-touristic areas. Thus, respondents usually express more positive and negative perceptions and a less number of 'don't know/not applicable' responses.

Similarly, Rosselló and Bujosa (2005) conclude, analysing tourism in the Balearic Islands, that the results show that more tourism development entails to greater permissiveness by residents, a more favourable attitude towards tourism and more unconcerned about negative impacts on the environment. All of which are related to the economic dependence of the municipalities in the tourist activity. In any case, this will not be so conclusive or so linear, as other authors conclude, comparing the residents' perceptions towards tourism in Majorca and Tenerife (Garau-Vadell et al., 2014), that in Majorca, which has a greater tourism development and a greater dependence on the sector, the residents' perceptions are more critical than those of the residents of Tenerife.

From the estimates obtained (Table 8), it can be concluded that those who tend to respond that tourism is important for their municipality are mainly those respondents who (1) reside in tourist municipalities (San Bartolomé de Tirajana and Mogán); (2) reside in the capital (Las Palmas de Gran Canaria); (3) are older; (4) have had frequent interaction with tourists; (5) agree or agree very much with the judgement that the quality of the tourists who visit our island has improved in the last years; (6) agree or agree very much with the judgement that it is necessary to try to increase the number of persons who visit the island; and (7) agree or agree very much with the judgement that 
Table 8. Estimates on the importance of tourism in the economy of the Municipality.

\begin{tabular}{lccrrr}
\hline & & & & \multicolumn{2}{c}{ Confidence interval } \\
\cline { 5 - 6 } Variable & Coefficient & Standard error & $t$-Ratio & Lower bound & Higher bound \\
\hline Constant & 0.1241 & 0.5876 & 0.21 & -1.0275 & 1.2757 \\
TOURMUNICIP & 3.6263 & 0.3163 & 11.46 & 3.0064 & 4.2463 \\
LPGC & 1.3320 & 0.2504 & 5.32 & 0.8413 & 1.8227 \\
AGE & 0.0141 & 0.0069 & 2.05 & 0.0006 & 0.0275 \\
TOURISINTER & 0.9855 & 0.3412 & 2.89 & 0.3167 & 1.6543 \\
PPI0_4 & -0.4236 & 0.2555 & -1.66 & -0.9244 & 0.0771 \\
PPI0_7 & 0.5806 & 0.2370 & 2.45 & 0.1160 & 1.0452 \\
PPI0_9 & 0.6852 & 0.2460 & 2.78 & 0.2030 & 1.1674 \\
PPI4_6 & -0.3027 & 0.2136 & -1.42 & -0.7215 & 0.1160 \\
PPI4_7 & 0.6159 & 0.3080 & 2.00 & 0.0122 & 1.2196 \\
$\mu_{1}$ & 2.1218 & 0.1479 & 14.34 & 1.8319 & 2.4117 \\
$\mu_{2}$ & 4.0855 & 0.1687 & 24.22 & 3.7549 & 4.4161 \\
\hline
\end{tabular}

Source: Own elaboration.

Table 9. Opinions about the tourists of Gran Canaria.

\begin{tabular}{lclrlc}
\hline & Purchasing power & & Behaviour & Respect for the environment \\
\hline DK/NA & 2.5 & DK/NA & 0.8 & DK/NA & 5.8 \\
High & 16.0 & Very nice & 6.0 & Very respectful & 13.7 \\
Medium & 65.5 & Nice & 68.1 & Enough & 61.5 \\
Low & 16.0 & Normal & 22.4 & Little & 15.6 \\
& & Unpleasant & 2.0 & Not at all & 3.4 \\
& & Very unpleasant & 0.7 & & \\
\hline
\end{tabular}

Source: Own elaboration.

Note: DK/NA: Don't know / Not Applicable.

as the construction has stagnated in the last recession years tourism has become the main exit of the crisis.

Contrarily, those who tend not to consider tourism as important for the municipality are those who (1) agree or agree very much with the judgement that facing the future, it would be necessary to resign from the tourism and to think about other alternative developments, and (2) agree or agree very much with the judgement that the tourist moratorium has stopped the investments and the tourist growth in the Canary Islands.

\section{Residents' perceptions towards tourists: Purchasing power, behaviour and respect for the environment}

In relation to the specific residents' perception towards the tourists themselves, the questionnaire includes three relevant issues: (1) the purchasing power; (2) the general behaviour; and (3) the respect for the environment (Table 9). 
Table 10. Estimates of the purchasing power of tourists.

\begin{tabular}{lrrrrr}
\hline & & & & \multicolumn{2}{c}{ Confidence interval } \\
\cline { 5 - 6 } Variable & Coefficient & Standard error & $t$-Ratio & Lower bound & Higher bound \\
\hline Constant & 2.2871 & 0.6724 & 3.40 & 0.9693 & 3.6050 \\
AGE & -0.0491 & 0.0075 & -6.57 & -0.0638 & -0.0345 \\
LPGC & 0.4828 & 0.2418 & 2.00 & 0.0089 & 0.9566 \\
TOURJOB & -0.3822 & 0.2176 & -1.76 & -0.8086 & 0.0443 \\
TOURISINTER & 0.5313 & 0.3686 & 1.44 & -0.1911 & 1.2536 \\
TOURISTREATM & 1.0581 & 0.3825 & 2.77 & 0.3085 & 1.8077 \\
PPI0_I & -0.5397 & 0.2337 & -2.31 & -0.9977 & -0.0817 \\
PPI0_2 & 0.4895 & 0.2125 & 2.30 & 0.0729 & 0.9060 \\
PPI0_3 & 0.5962 & 0.2147 & 2.78 & 0.1754 & 1.0169 \\
PPI0_7 & 1.2251 & 0.2445 & 5.01 & 0.7458 & 1.7043 \\
PPI0_8 & 0.7173 & 0.2104 & 3.41 & 0.3049 & 1.1296 \\
PPI4_2 & -0.6305 & 0.2527 & -2.49 & -1.1258 & -0.1352 \\
$\mu_{1}$ & 4.2668 & 0.2359 & 18.09 & 3.8045 & 4.7291 \\
\hline
\end{tabular}

Source: Own elaboration.

Mostly, residents consider that the tourists' purchasing power is 'medium' (65.5\%). While only $16 \%$ consider that it is 'high' or 'low', respectively. The emergence and permanence of low-cost airlines, the decrease of prices for international flights, the implementation of the 'all-inclusive' modality as well as the new forms of accommodation within the framework of the so-called 'collaborative economy' would have allowed more tourists to come to Gran Canaria for holidays. Until not so long ago, the trip to Gran Canaria was significantly more expensive, tourists' purchasing power was higher, and tourists' expenditure per person in the destination was also higher.

Regarding the general behaviour of tourists, it can be seen that it is valued as nice for almost 7 (68.1\%) out of 10 respondents; $22.4 \%$ consider it as normal, and, significantly, it is noteworthy that unpleasant or very unpleasant behaviour is only seen by a very small percentage of residents $(2.7 \%)$. This result reveals that besides being a mature destination there are no conflicts between tourists and residents. This feature is of a vital importance considering the recent episodes of 'tourism-phobia' that have occurred in other Spanish destinations.

Working in tourism is another important determinant factor of the residents' perceptions towards tourists. Vargas-Sánchez et al. (2014) find that residents who receive a greater personal benefit perceive tourists in a more positive way, both in personal treatment and in the tourist expenditure. The authors also find, including as a determinant factor the 'behaviour' of tourists, that there exists a direct relationship between a good concept on this behaviour and an increase in the positive perception of the impacts of tourism.

Regarding the tourists' respect for the environment, the valuation is also positive, as almost 8 (75.2\%) out of every 10 respondents evaluate it as enough or very respectful. It should be noted that, in the island of Gran Canaria, one out of four tourists are Scandinavian. Tourists who come from societies where, in general, environmental respect and ecological values are transmitted from an early age in initial education.

Considering the estimates obtained (Table 10), it can be seen that the residents who most likely consider that the purchasing power of tourists is high are characterized by those who (1) reside in 
Table II. Estimates of the behaviour of tourists.

\begin{tabular}{lrrrrr}
\hline & & & & \multicolumn{2}{c}{ Confidence interval } \\
\cline { 5 - 6 } Variable & Coefficient & Standard error & $t$-Ratio & Lower bound & Higher bound \\
\hline Constant & 5.3220 & 0.4098 & 12.99 & 4.5188 & 6.1252 \\
AGE & -0.0187 & 0.0068 & -2.76 & -0.0319 & -0.0054 \\
TOURJOB & 0.6309 & 0.1990 & 3.17 & 0.2408 & 1.0210 \\
HASTRAV & -0.2939 & 0.1979 & -1.48 & -0.6817 & 0.0940 \\
PPI0_2 & 0.5474 & 0.2100 & 2.61 & 0.1359 & 0.9589 \\
PPI0_7 & 0.6800 & 0.2312 & 2.94 & 0.2268 & 1.1331 \\
PPI0_8 & 0.6017 & 0.2008 & 3.00 & 0.2081 & 0.9954 \\
$\mu_{1}$ & 1.3303 & 0.2661 & 5.00 & 0.8088 & 1.8519 \\
$\mu_{2}$ & 4.0459 & 0.1911 & 21.17 & 3.6712 & 4.4205 \\
$\mu_{3}$ & 8.0832 & 0.2260 & 35.77 & 7.6403 & 8.5261 \\
\hline
\end{tabular}

Source: Own elaboration.

Las Palmas de Gran Canaria; (2) have frequent interaction with tourists; (3) consider that the treatment given to tourists is good; (4) agree with the judgement that tourism has a positive effect on the natural resources and the landscape; (5) agree with the judgement that most of the jobs that tourism creates are occupied by immigrants; (6) agree with the judgement that the quality of tourists who visit the island has improved in recent years; and (7) agree with the judgement that tourist offer (hotels and restaurants) of Gran Canaria is of very good quality. On the other hand, those who are older, work or have worked in tourism or agree with the judgements that the jobs generated by tourism are of poor quality, and that tourists spend little money generating few benefits, are the ones who tend to consider that the purchasing power of tourists is low.

In relation to the behaviour of the tourists, those who have major probability of thinking that it is nice or very nice are the residents who work or have worked in tourism and agree with the following judgements: (1) tourism has a positive effect on the natural resources and the landscape; (2) the quality of tourists who visit the island has improved in recent years; and (3) the tourist offer of Gran Canaria is of very good quality (Table 11).

On the contrary, those residents who would most say that the behaviour of tourists is rather unpleasant are the older people and those who have travelled in the last 12 months. It should be noted that age is usually one of the socio-demographic variables that most affect the opinions on tourism development (Mc Gehee and Anderek, 2004). Usually, at an older age, there are less favourable opinions about tourism and tourists, as has been published in the cases of Andalusia, the Gold Coast region in Australia and Samos Island in Greece (Fredline and Faulkner, 2000; Haralambopoulos and Pizam, 1996; Moreira, 2011).

Regarding the residents' perception on the tourists' respect for the environment (Table 12), respondents who most likely consider that tourists are very respectful for the environment are mainly characterized by (1) being the elderly segment; (2) residing in a tourist municipality; (3) having a relative who works or has worked in tourism; agreeing with the judgements that (4) tourism has a positive effect on natural resources and landscape; (5) the tourist offer in Gran Canaria is of very good quality; (6) the eventual oil explorations will endanger the beaches of Fuerteventura and Lanzarote as tourist resources; and (7) the tourist area of the south of the island has too many obsolete facilities and must be renewed. 
Table 12. Estimates of tourists' respect for the environment.

\begin{tabular}{lrrrrr}
\hline & & & & \multicolumn{2}{c}{ Confidence interval } \\
\cline { 5 - 6 } Variable & Coefficient & Standard error & t-Ratio & Lower bound & Higher bound \\
\hline Constant & 1.5181 & 0.6868 & 2.21 & 0.1720 & 2.8643 \\
AGE & 0.0209 & 0.0066 & 3.19 & 0.0081 & 0.0338 \\
TOURMUNICIP & 1.0915 & 0.2145 & 5.09 & 0.6710 & 1.5120 \\
TOURJOBRELATIVE & 0.6708 & 0.2113 & 3.17 & 0.2567 & 1.0849 \\
TOURISTREATM & -1.0218 & 0.3849 & -2.65 & -1.7761 & -0.2675 \\
PPI0_I & -0.6310 & 0.2138 & -2.95 & -1.0500 & -0.2121 \\
PPI0_2 & 0.7810 & 0.1980 & 3.94 & 0.3929 & 1.1691 \\
PPI0_8 & 0.4372 & 0.1924 & 2.27 & 0.0601 & 0.8143 \\
PPI4_5 & 0.3475 & 0.2061 & 1.69 & -0.0564 & 0.7514 \\
PPI4_8 & 1.0731 & 0.4698 & 2.28 & 0.1523 & 1.9938 \\
$\mu_{1}$ & 2.0836 & 0.1596 & 13.06 & 1.7708 & 2.3964 \\
$\mu_{2}$ & 5.4695 & 0.1911 & 28.62 & 5.0949 & 5.8440 \\
\hline
\end{tabular}

Source: Own elaboration.

The respondents who would mainly consider that tourists' respect for the environment is little or inexistent are also the ones who believe that the treatment given to tourists is good or very good, and agree with the judgement that the jobs generated by tourism are of poor quality.

\section{Conclusions}

The residents of Gran Canaria are a population quite conscious and critical with respect to one of the main economic sectors of the island: the tourism. It is noteworthy that in the survey the percentage of questions without answer has been statistically non-significant. Thus, it can be inferred that residents have formed an opinion regarding this phenomenon and they are confident expressing it. On the other hand, it should be noted that tourism represents one-third of the regional GDP and one-third of the direct jobs.

Emphasizing the results of the study, we note that among the most important impacts of tourism, the analysis will be mainly focussed on those related to the creation of new jobs, the generation of wealth and economic growth and the development of the infrastructures. In addition, as the majority of respondents believe that tourism is quite important for the economy of the municipality of residence, demonstrating the multiplier effect of the impacts of this sector in the whole island, the determinants of this effect were also studied.

In general terms, it was concluded that the positive influence of tourism and tourists in the destination is more likely observed by those residents who (1) reside in a tourist municipality; (2) reside in the capital city; (3) live in couple; (4) are men; (5) have an income less than 1500€; and (6) have had a frequent interaction with tourists.

In addition, some determinant factors show ambivalent results as, for example, those who work or have worked in tourism and those who have travelled in the last 12 months have a negative influence in the probability of having a positive perception in some of the issues under analysis. For the majority of the issues under analysis, it was also observed that being older have a negative influence in having a positive perception towards tourism and tourists. 
About the residents' perceptions on tourists themselves, most of the respondents consider as 'medium', 'nice' and 'respectful' their purchasing power level, their overall behaviour and their respect for the environment, respectively.

It is necessary to emphasize finally the difficulty in the task of establishing relations between the analysed determinant factors and its varied nuances. Thus, the innate complexity of this type of studies on the residents' perceptions was again illustrated. On the other hand, in this field of study, up to now, there is no academic consensus that allows to extrapolate significant conclusions or to share solid methodological and theoretical standards. This is due, among other things, to the inherent complexity of the tourist systems integrated by various subsystems, to the enormous variety of contexts of each case study, to the different cultures involved, to the realities inherent in each destination, and to their respective and different states in the life cycles of the tourist product.

Recently, Spain has become an important actor regarding the existence of an increased society polarity, and more than ever, antagonism expressions exist both in favour and against tourism and the different development models. Thus, future studies on the positive and negative impacts of tourism on target populations would be highly effective and, especially, useful for public managers. Trying to minimize the negative impacts and maximize the positive impacts could counteract possible hostilities against tourists. In this respect, tourist awareness campaigns for the resident population less related to tourism could be developed in order to reduce the potential impacts associated to the negative social conscience created by 'over tourism' campaigns.

For these reasons, this article contributes shedding more light in this controversial field on the residents' social perception towards tourism and tourists, analysing the reality of a consolidated and mature destination of sun and beach. Future analyses will be able to contribute with new research methodological proposals that study other products and tourist destinations, and through, for example, the use of qualitative techniques of social research contributing with new and necessary explanatory theories.

\section{Acknowledgements}

The authors wish to thank the editor and the anonymous reviewers for their advice and comments which have contributed to the improvement of this article. This work benefits from a research project INNOVA-FULP. The usual disclaimer applies.

\section{Declaration of conflicting interests}

The author(s) declared no potential conflicts of interest with respect to the research, authorship, and/or publication of this article.

\section{Funding}

The author(s) disclosed receipt of the following financial support for the research, authorship, and/or publication of this article: The first author receives funds from the Innova Grant of the University of Las Palmas de Gran Canaria Foundation.

\section{ORCID iDs}

Pedro Ernesto Moreira Gregori (D) https://orcid.org/0000-0003-1985-5394

Juan Carlos Martín (D) https://orcid.org/0000-0002-2950-2405

\section{References}

Andereck K, Valentine K, Knopf R, et al. (2005) Residents' perceptions of community tourism impacts. Annals of Tourism Research 32(4): 1056-1076. 
Ap J (1992) Residents' perceptions on tourism impacts. Annals of Tourism Research 19(4): 665-690.

Ap J and Crompton J (1993) Residents' strategies for responding to tourism impacts. Journal of Travel Research 32(1): 47-50.

Capocchi A, Vallone C, Pierotti M, et al. (2019) Overtourism: a literature review to assess implications and future perspectives. Sustainability 11(12): 3303.

Davis D, Allen J and Cosenza RM (1988) Segmenting local residents by their attitudes, interests, and opinions toward tourism. Journal of Travel Research 27(2): 2-8.

Dodds R and Butler R (2019) The phenomena of overtourism: a review. International Journal of Tourism Cities 5(4): 519-528.

Dogan HZ (1989) Forms of adjustment: sociocultural impacts of tourism. Annals of Tourism Research 16(2): 216-236.

Doxey GV (1975) A causation theory of visitor-resident irritants: methodology and research inferences. In Travel and Tourism Research Associations Sixth Annual Conference Proceedings, San Diego, CA, USA, 8-11 September 1975, pp. 195-198.

Fredline E and Faulkner B (2000) Host community reactions. A cluster analysis. Annals of Tourism Research 27(3): 763-784.

Garau-Vadell JB, Díaz-Armas R and Gutierrez-Taño D (2014) Residents' perceptions of tourism impacts on island destinations: a comparative analysis. International Journal of Tourism Research 16(6): $578-585$.

Greene W (2015) NLOGIT Version 6.0. Reference Guide. Plainview, NY: Econometrics Software Inc.

Greene WH and Hensher DA (2010) Modeling Ordered Choices. A Primer. Cambridge: Cambridge University Press.

Haralambopoulos N and Pizam A (1996) Perceived impacts of tourism: the case of Samos. Annals of Tourism Research 23(3): 503-526.

Harrill R (2004) Residents' attitudes toward tourism development: a literature review with implications for tourism planning. Journal of Planning Literature 18: 250-266.

Harrill R and Potts T (2003) Tourism planning in historic districts: attitudes toward tourism development in Charleston. Journal of the American Planning Association 69(3): 233-244.

Li R, Peng 1 and Deng W (2019) Resident perceptions toward tourism development at a large scale. Sustainability 11(18): 5074.

Marrero JR and Huete R (2013) La opinión pública sobre el empleo turístico en la Comunidad Valenciana. Cuadernos de Turismo 32:189-206.

Mason Peter and Cheyne J (2000) Residents' attitudes to proposed tourism development. Annals of Tourism Research 27(2): 391-411.

Mc Gehee N and Anderek K (2004) Factors predicting rural residents' support for tourism. Journal of Travel Research 43(2): 131-140.

Mccool SF and Martin SR (1994) Community attachment and attitudes toward tourism development. Journal of Travel Research 32(2): 29-34.

Mckelvey R and Zavoina WA (1975) Statistical model for the analysis of ordered level dependent variables. The Journal of Mathematical Sociology 1975(4): 103-120.

Monterrubio JC (2008) Residents' perception of tourism: a critical theoretical and methodological review. CIENCIA ergo-sum 15(1): 35-44.

Moreira P (2011) Percepción social del turismo en Andalucía-España. Revista Gaudeamus, Universidad Latina de Costa Rica 3(1): 133-157.

Moreira P (2014) Opinión pública y turismo en Gran Canaria. In: II Foro Internacional de Turismo Maspalomas Costa Canaria. Maspalomas: Universidad de Las Palmas de Gran Canaria, pp. 429-449.

Moreira P, Martin JC and Román C (2017) Tourism and residents in Gran Canaria. Local opinions according to labour linkage in tourism sector. In II Spring Symposium on Challenges in Sustainability Tourism Development. Maspalomas: Universidad de Las Palmas de Gran Canaria. 
Nunkoo R, Smith S and Ramkissoon M (2013) Resident attitudes to tourism: a longitudinal study of 140 articles from 1984 to 2010. Journal of Sustainable Tourism 21(1): 5-25.

Pearce R, Moscardo G and Ross G (1996) Tourism Community Relationships. Oxford, UK: Elsevier Science Ltd.

Robinson D, Newman SP and Stead SM (2019) Community perceptions link environmental decline to reduced support for tourism development in small island states: a case study in the Turks and Caicos Islands. Marine Policy 108: 103671.

Rodríguez González P (2007) Los andaluces y el turismo: percepción social del turismo en Andalucía. Sevilla: Consejería de Turismo de Andalucía.

Rosselló J and Bujosa A (2005) Determinantes de la actitud ambiental frente al turismo: una aplicación para el caso de los residentes de las Islas Baleares. Papers de Turisme 37-38: 45-56.

Sharpley R (2014) Host perceptions of tourism: a review of the research. Tourism Management 42: 37-49.

Snaith T and Haley A (1999) Residents' opinions of tourism development in the historical city of York. Tourism Management 20(5): 595-603.

Tosun C (2002) Host perceptions of impacts: a comparative tourism study. Annals of Tourism Research 29(1): 231-253.

Vargas-Sánchez A, Porras-Bueno N and de los Ángeles Plaza-Mejía M (2014) Residents' attitude to tourism and seasonality. Journal of Travel Research 53(5): 581-596.

Vázquez AMB, Barrera-Fernández D and Hernández-Escampa M (2017) The sociocultural impact of tourism in Benalmádena. International Journal of Scientific Management and Tourism 3(1): 29-45.

\section{Author biographies}

Pedro Ernesto Moreira Gregori obtained his PhD in Tourism, Economics and Management of the Doctoral School at the University of Las Palmas de Gran Canaria, Spain. He also completed his Master of Science programme in Tourist Management at the University of the Balearic Islands and his Master of Science in Social Problems at the National Distance Education University in Spain. He is also a sociologist and his main fields of research are tourism and social perception where he has published his main contributions.

Concepción Román is a full professor at the Department of Applied Economic Analysis at the University of Las Palmas de Gran Canaria. She is an active researcher at the Institute of Tourism and Sustainable Economic Development. She is the Head of the Research Group Tourism and Transport and has authored or co-authored more than 75 peer-reviewed papers and book chapters in her area of expertise: Discrete Choice Analysis in Tourism and Transport. She has taught numerous international courses in her field.

Juan Carlos Martín is a full professor at the Department of Applied Economic Analysis at the University of Las Palmas de Gran Canaria. He is an active researcher at the Institute of Tourism and Sustainable Economic Development. He has authored or co-authored more than 80 peer-reviewed papers and book chapters in his area of expertise: Tourism and Transport Economics. He likes to teach to international students. 